\title{
O Efeito da Audiência na Interação com Chatbots em Espaços Físicos
}

\author{
Heloisa Candello \\ IBM Research \\ hcandello@br.ibm.com
}

\author{
Claudio Pinhanez \\ IBM Research \\ csantosp@br.ibm.com
}

\author{
Mauro Pichiliani \\ IBM Research \\ mpichi@br.ibm.com
}

\author{
Paulo Cavalin \\ IBM Research \\ pcavalin@br.ibm.com
}

\author{
Flavio Figueiredo \\ Univ. Fed. Minas Gerais \\ flaviovdf@dcc.ufmg.br
}

\author{
Marisa Vasconcelos \\ IBM Research \\ marisaav@br.ibm.com
}

\author{
Haylla Do Carmo \\ IBM Research \\ hayllat@br.ibm.com
}

\begin{abstract}
RESUMO
Como a presença de audência influencia a interação social com um sistema conversacional em um espaço físico? Para responder a essa questão, esta pesquisa analisou dados de uma exposição de arte em que os visitantes interagiam em linguagem natural com três chatbots representando personagens de um livro. Foram realizados dois estudos para explorar a influência das audiências. No Estudo 1 o trabalho em campo coletou e analisou de forma cruzada a percepção da interação social relatada, as condições da audiência (o visitante está sozinho, o visitante é observado por conhecidos e/ou estranhos) e variáveis de controle, como o gênero do visitante e a familiaridade com o livro. No Estudo 2 foram analisadas mais de 5.000 registros de conversas e gravações de vídeo, identificando padrões de diálogo e como eles se correlacionaram com as condições do público. Alguns efeitos significativos foram encontrados, sugerindo que sistemas conversacionais em espaços físicos devem ser projetados considerando se outras pessoas observam o usuário ou não.
\end{abstract}

\section{PALAVRA-CHAVE}

Sistemas Conversasionais, Efeitos de Audiência, Design de Chatbots.

\section{Introdução}

Os sistemas de conversação estão sendo cada vez mais empregados em espaços físicos para uso público e privado. Com estes sistemas, ou chatbots, as interações humanas podem acontecer na presença de audiência, seja amigos, familiares ou simplesmente estranhos e espectadores.

Permission to reproduce or distribute, in whole or in part, material extracted from this work, verbatim, adapted or remixed, as well as the creation or production from the content of such work, is granted without fee for non-commercial use, provided that the original work is properly credited. IHC 2019 - TRILHA ARTIGOS INTERNACIONAIS, Outubro 21-25, 2019, Vitória, Brasil. In Anais Estendidos do XVIII Simpósio Brasileiro sobre Fatores Humanos em Sistemas

Computacionais. Porto Alegre: SBC. (C) 2019 by the author(s), in accordance with the terms of the Creative Commons Attribution-NonCommercial 4.0 International Public License (CC BY-NC 4.0).
Estudos relacionados descobriram que os seres humanos tendem a mudar seu comportamento normal de conversa quando estão na frente dos outros [1,3]. Entender essas mudanças no comportamento é importante porque pode ser necessário projetar os sistemas de conversação da máquina para lidar com situações em que as pessoas mudam seu comportamento habitual para acomodar a presença de uma audiência. A motivação para estudar esse tipo de mudança de comportamento teve origem nas observações iniciais de visitantes que vivenciavam uma exposição de arte por meio da interação com um grupo de chatbots, sozinhos ou na presença de conhecidos e/ou estranhos.

Ao reconhecer o contexto da audiência, o sistema conversacional pode ser projetado para responder apropriadamente a interação social em grupo, adaptando-se e aprimorando a experiência geral dos usuários e de seus públicos.

No entanto, essas considerações e estratégias só fazem sentido se entendermos se e como os usuários mudam seu comportamento ao conversar com máquinas na frente de outras pessoas. Eles se sentem mais envergonhados, poderosos ou mais espertos por um público ao dialogar com uma máquina em vez de com uma pessoa? As mudanças são diferentes se o público for formado por conhecidos ou estranhos? Para esclarecer essas questões, dois estudos no cenário de uma exposição de arte interativa e seus visitantes foram conduzidos.

Neste cenário um ou vários visitantes conversavam livremente em um espaço físico com três chatbots baseados em texto representando personagens do livro Dom Casmurro de Machado de Assis. Um estudo em campo exploratório foi feito durante as últimas três semanas de Agosto de 2017 no museu onde a obra de arte foi exposta. Nesse período 5.100 pessoas interagiram com a exposição. Esses participantes foram filmados e cerca de 10.000 perguntas foram registradas. Destes visitantes, 92 foram observados durante a interação com a exposição e convidados a participar de uma entrevista semiestruturada. As seguintes questões de pesquisa foram exploradas:

RQ1. Quais são os efeitos da audiência nas percepções dos usuários durante a interação social com os chatbots? 
RQ2. A presença de audiência influencia o tipo e o conteúdo das perguntas do usuário direcionadas aos chatbots?

No primeiro estudo entrevistas semi-estruturadas e observações revelaram um conjunto de temas emergentes que ajudaram a criar uma imagem da experiência dos visitantes com a obra de arte: curiosidade e novidade; interesse na trama; respostas esperadas dos chatbots; e efeitos da audiência.

No segundo estudo analisamos um conjunto de dados com aproximadamente 5.000 perguntas registradas durante três semanas combinadas com informações extraídas das gravações de vídeo das interações. Nessa análise, empregamos ferramentas de codificação manual e de aprendizado de máquina para analisar o conjunto de dados usando uma abordagem semi-supervisionada.

Tanto no Estudo 1 como no Estudo 2 encontramos evidências de efeitos da audiência sobre como as pessoas interagem com os chatbots em espaços públicos.

No Estudo 1, vimos que diferentes condições de audiência produziram efeitos significativos na experiência do usuário reportada pelos usuários, conforme medido pelo nosso questionário. Quando os usuários eram observados por conhecidos, os usuários sentiam menos que os personagens respondiam às suas perguntas do que os usuários nas outras condições, às vezes conversando diretamente com as pessoas que conheciam através da obra de arte. Por outro lado, os usuários observados por estranhos que esperavam na fila relataram com mais freqüência que os personagens estavam conversando com eles na comparação com os usuários das outras condições. Uma possível explicação é que esses usuários podem ter tentado se concentrar mais na conversa com os chatbots porque se sentiam pressionados por pessoas que esperavam por trás deles.

Também vimos no Estudo 1 que os usuários com conhecimento prévio da história representada na obra de arte pareciam ser mais fortemente afetados pelas condições da audiência. Tais usuários, quando observados por conhecidos, discordaram significativamente de que os personagens falavam entre si, demonstrando um aumento no sentimento de pertencer à conversa. Da mesma forma, usuários observados por estranhos na fila e familiarizados com a trama do livro eram significativamente mais propensos a perceber os chatbots conversando com eles, a se sentir parte da conversa e a acreditar que os personagens respondiam às suas perguntas além de tender a discordar de que os personagens estavam conversando entre si.

Quando os usuários conheciam o contexto e eram observados por estranhos ao redor da mesa houve um aumento significativo na percepção de que os personagens podiam falar sobre qualquer assunto. De alguma forma, o conhecimento prévio do conteúdo possivelmente impulsionou o efeito da audiência na percepção das interações sociais nas situações onde um público familiar está ao redor os usuários ou quando os usuários são observados por estranhos. Também vimos que os efeitos da audiência sobre os usuários foram mais pronunciados quando considerados em conjunto com o gênero e o tipo de perguntas que homens e mulheres enviaram para os chatbots.
No Estudo 1 também vimos evidências de que os efeitos da audiência são diferentes de acordo com o gênero do usuário, particularmente considerando a presença de estranhos. As usuárias observadas por estranhos na fila sentiram mais que os personagens conversaram com elas, enquanto os usuários do sexo masculino não relataram isso. Quando observadas por estranhos ao redor da mesa, as usuárias perceberam que os chatbots não falavam sobre outros assuntos em maior extensão $\mathrm{e}$ significativamente mais do que os usuários do sexo masculino. Nossas evidências parecem indicar que o gênero masculino se comportará melhor quando conhecidos não os observam. Em contraste, a análise qualitativa do Estudo 1 mostra que quando os homens fazem perguntas fora do escopo, suas sentenças intensificam o comportamento de se gabar (showing off) com mais frequência. Resultados semelhantes existem na literatura [2].

O Estudo 2 revelou outros tipos de efeitos da audiência complementares aos detectados no Estudo 1: as reações dos usuários às falhas do chatbot foram mais comuns quando os usuários foram observados por conhecidos. Também vimos que os participantes do sexo masculino tinham uma tendência maior a perguntar algo relacionado ao escopo do livro quando estavam perto de uma audiência de estranhos ao redor da mesa.

O Estudo 2 também mostrou efeitos da audiência aprimorados quando havia um uma menção direta ao usuário na resposta do chatbot, i.e. o nome do usuário ou o pronome na terceira pessoa do singular é citado na resposta. Em geral, descobrimos que a menção direta aumentou a probabilidade de o usuário reagir a uma falha do chatbot. No entanto, uma experiência compartilhada com conhecidos combinada com a menção direta tendeu a reduzir a reação ao fracasso.

Em resumo, os dois estudos reuniram evidências suficientes para apoiar respostas positivas às duas perguntas de pesquisa RQ1 e RQ2, e apontam para a necessidade de considerar os efeitos da audiência ao projetar experiências de conversação em espaços físicos. Esses efeitos da audiência podem ser afetados por muitos fatores, tais como: a composição do público (conhecidos ou estranhos); a existência de uma fila de espera; o conhecimento do contexto da interação; gênero dos usuários; e uso de menção direta.

\section{REFERÊNCIAS}

[1] Harry Brignull and Yvonne Rogers. 2003. Enticing People to Interact with Large Public Displays in Public Spaces. In Conference: Human-Computer Interaction INTERACT '03: IFIP TC13 International Conference on HumanComputer Interaction, 1st-5th September 2003, Zurich, Switzerland.

[2] N. B. Cottrell, D. L. Wack, G. J. Sekerak, and R. H Rittle. 1968. Social facilitation of dominant responses by the presence of an audience and the mere presence of others. Journal of Personality and Socia Psychology 9, 3 (1968), 245-250.

[3] Stuart Reeves. 2011. Designing Interfaces in Public Settings: Understanding the Role of the Spectator in Human-Computer Interaction (1st ed.). Springer Publishing Company, Incorporated. 